\title{
Prevalence, Risk Factors and Intra-Hospital Outcomes Relating to Peri-Intraventricular Hemorrhage in Premature Newborns of Gestational Age Less than 34 Weeks
}

\author{
Ana Frante de Holanda Pinto Vasconcelos ${ }^{1}$, Kaliny da Silva Galvão1, Rodrigo Daudt Tenório', \\ Ana Clara Monteiro Laranjeira², Délia Maria de M. L. Herrmann33, Diêgo Lucas Ramos e Silva², \\ Juliana Barbosa Nunes Cavalcante ${ }^{2}$, Jamille Campos Sousa ${ }^{3}$, Euclides Maurício Trindade Filho ${ }^{*}$ \\ ${ }^{1}$ Biological Science Nucleus, Cesmac University Center, Maceió, Alagoas, Brasil \\ ${ }^{2}$ Biological Science Nucleus, State University of Health Science of Alagoas-UNCISAL, Maceió, Alagoas, Brasil \\ ${ }^{3}$ Department of Biological Science, Federal University of Alagoas, Maceió, Alagoas, Brasil \\ Email: *emtfilho@gmail.com
}

How to cite this paper: de Holanda Pinto Vasconcelos, A.F., da Silva Galvão, K., Tenório, R.D., Laranjeira, A.C.M., de M. L. Herrmann, D.M., e Silva, D.L.R., Cavalcante, J.B.N., Sousa, J.C. and Filho, E.M.T. (2021) Prevalence, Risk Factors and Intra-Hospital Outcomes Relating to Peri-Intraventricular Hemorrhage in Premature Newborns of Gestational Age Less than 34 Weeks. Open Journal of Obstetrics and Gynecology, 11, 898-910.

https://doi.org/10.4236/ojog.2021.117084

Received: June 19, 2021

Accepted: July 20, 2021

Published: July 23, 2021

Copyright $\odot 2021$ by author(s) and Scientific Research Publishing Inc. This work is licensed under the Creative Commons Attribution International License (CC BY 4.0).

http://creativecommons.org/licenses/by/4.0/

(c) (i) Open Access

\begin{abstract}
Peri-intraventricular hemorrhage is one of the main causes of neurological impairment in premature newborns. To control their risk factors is necessary in view of the increasing survival of extreme preterm infants. Objective: To evaluate the prevalence of peri-intraventricular hemorrhage in premature newborns, identify the risk factors and observe the frequencies of intra-hospital outcomes of interests. Methods: This study was done in Brazil. This was an observational, analytical longitudinal and prospective study. The subjects included were newborns of gestational age less than 34 weeks who were admitted to two public hospitals between May and November 2015. To assess possible associated factors, obstetric, perinatal and neonatal data were analyzed (chorioamnionitis, antenatal corticosteroids, gestational age, newborn weight, Apgar score at 1 and 5 minutes, resuscitation in the delivery room, surfactant in the delivery room, newborn transferred from another hospital, respiratory distress syndrome: RDS, sepsis, umbilical vein catheterization, assisted ventilation, exogenous surfactant in the Neonatal ICU, use of sodium bicarbonate, inotropic agents, adrenaline, volume expanders and blood products). The hospital outcomes studied were assisted ventilation time, hospital stay and death. The data analysis was performed by chi-square test or Fisher's test, with a significance level of 5\%. Results: Out of 156 newborns, 46 (29.9\%) presented peri-intraventricular hemorrhage and $28.2 \%$ of these had a severe form of the disease. There were significant associations $(p<0.05)$ with the
\end{abstract}


following risk factors: gestational age, birth weight, low Apgar score, delivery room resuscitation, RDS, surfactant use, sepsis, packed red blood cell transfusion, mechanical ventilation and umbilical vein catheterization. The newborns with peri-intraventricular hemorrhage presented longer times on assisted ventilation, longer hospital stays and higher risk of death. Conclusion: The prevalence of peri-intraventricular hemorrhage was high in the population studied, especially the severe form. Perinatal and neonatal risk factors were associated with a higher risk of developing the disease and the outcomes studied were more evident in these newborns.

\section{Keywords}

Premature Newborn, Peri-Intraventricular Hemorrhage, Risk Factors, Transfontanelle Ultrasonography

\section{Introduction}

With the advances in perinatal medicine and neonatal intensive care that have been achieved, there has been a significant increase in survival among premature newborns. However, it has been observed that the incidence of neurological impairment among these newborns continues to be high, and peri-intraventricular hemorrhage is one of its main causes [1] [2] [3] [4]. Peri-intraventricular hemorrhage typically begins in the subependymal germinal matrix, which is a richly vascularized region in the developing brain, but with limited capacity for self-regulation of the cerebral blood flow [5].

At the beginning of the 1980s, the incidence of peri-intraventricular hemorrhage was 50\% [5]. In a recent study, morbidity among premature newborns was evaluated and, in comparing the frequency of peri-intraventricular hemorrhage between Taiwan (China), Canada, Japan and the United States, it was observed that severe peri-intraventricular hemorrhage was diagnosed in $14.0 \%, 18.0 \%$, $10.0 \%$ and $19.0 \%$ of the cases, respectively [6]. In Brazil, data from 20 university hospitals that were presented in the 2014 annual report of the Brazilian Network for Neonatal Research showed that the incidence of peri-intraventricular hemorrhage among premature newborns weighing less than $1500 \mathrm{~g}$ was $30 \%$, and that this condition was severe in $9 \%$ of these cases [7].

The first classification system for peri-intraventricular hemorrhage was developed by Papile et al. (1978), using computed tomography [8]. This system was applied to cerebral ultrasonography and was found to have high sensitivity and specificity rates in relation to detecting peri-intraventricular hemorrhage. It has become widely used, and this continues today [9] [10].

The frequency of occurrence and severity of peri-intraventricular hemorrhage becomes greater when the gestational age and birth weight are lower [11] [12] [13]. However, several other prenatal factors (rupture of membranes, presence of chorioamnionitis or nonuse of antenatal corticoids), perinatal factors (low Ap- 
gar index, use of reanimation or use of surfactant) and postnatal factors (respiratory distress syndrome, sepsis, volume expanders, mechanical ventilation and use of drugs like inotropes and sodium bicarbonate) have been correlated with higher risk of developing the disease [1] [2] [14] [15].

Knowledge of the prevalence of peri-intraventricular hemorrhage among premature newborns and of the risk factors involved in each neonatal intensive care unit is necessary so that preventive measures can be brought in. Studying this condition is of great interest because of its association with increased neonatal morbidity and mortality, longer hospital stay and higher risk of development of cognitive and motor deficits.

Thus, the aim of the present study was to evaluate the prevalence of peri-intraventricular hemorrhage among premature newborns, identify the risk factors and observe the frequencies of intra-hospital outcomes of interest (duration of assisted ventilation, length of hospital stay and death).

\section{Material and Methods}

This study was approved by the Research Ethics Committee of the Cesmac University Center, under the number 1.064.913. The population was composed of premature newborns of gestational age between 25 weeks and 33 weeks and 6 days who were hospitalized in the neonatal intensive care units of two tertiary-level public university hospitals in the state of Alagoas between May and November 2015. Newborns with congenital malformations, those for whom no ultrasonography examination had been performed up to the fourth day of life and those who were transferred to other hospital services providing lower-complexity cases before the tenth day of life were excluded. The newborns who were transferred after the tenth day underwent the ultrasonography examinations of the protocol of the present study, and their outcomes of interest were followed up until the time of discharge from hospital. These newborns remained in the study group.

An echograph with 5 to $10 \mathrm{MHz}$ transducers (GE LOGIC P6) was used. For documentation purposes, the examinations were recorded on CDs for subsequent analysis. The images were obtained via the anterior and posterior fontanelles.

The population of this study underwent serial cerebral ultrasonography, within the first four days of life, on the $10^{\text {th }}$ and $28^{\text {th }}$ days and at discharge from hospital.

The newborns were stratified into three gestational age groups that took into consideration the level of development inherent to each stage: 25 weeks to 27 weeks and 6 days; 28 weeks to 30 weeks and 6 days; and 31 weeks to 33 weeks and 6 days [16].

Among the newborns with a diagnosis of peri-intraventricular hemorrhage, the widely used classification system proposed by Papile et al. (1978) was applied, namely: grade I—subependymal hemorrhage; grade II-intraventricular 
hemorrhage without dilatation; grade III-intraventricular hemorrhage with dilatation; and grade IV-presence of an echogenic area in the periventricular tissue with or without intraventricular hemorrhage. Hemorrhages of grades I and II are classified as mild; and those of grades III and IV as severe [8].

The data relating to the dependent variable (peri-intraventricular hemorrhage) were obtained through transfontanelle ultrasonography performed in the neonatal unit and were stored on a $\mathrm{CD}$ and catalogued using a specific form for this purpose. The data relating to the independent variables were gathered using data collection forms that contained questions relating to the pregnancy, birth and neonatal evolution until discharge from hospital. This information came from the medical records relating to both the mother and the newborn.

In the statistical analysis, the quantitative variables were presented in the form of means, standard deviations and minimums and maximums. The qualitative variables were presented in the form of frequency tables. In inferential statistical analyses, the presence of associations between the dependent variable and the independent variables was ascertained through the chi-square test or Fisher's exact test.

In all the analyses, the significance level was taken to be $\mathrm{p} \leq 0.05$. The data were tabulated using Excel electronic spreadsheets (Microsoft Office) and statistical inferences were made through the application SPSS 20.0.

\section{Results}

Over the period of this study, i.e. from May to November 2015, 176 newborns of gestational ages less than 34 weeks were admitted to the two neonatal intensive care units investigated. Twenty newborns (11.4\%) were excluded from the study: five because they died before the first ultrasonography examination could be performed; two because of malformation of the central nervous system; seven because no transfontanelle ultrasonography was performed; and six because they were transferred to hospitals providing care for lower-complexity cases before the tenth day of life. Among the 156 newborns who were eligible for inclusion, 46 (29.5\%) presented peri-intraventricular hemorrhage. The distribution of peri-intraventricular hemorrhage cases according to severity is shown in Table 1.

It was observed that $28.2 \%$ of the peri-intraventricular hemorrhage cases were

Table 1. Distribution of the severity of peri-intraventricular hemorrhage among newborns of gestational age less than 34 weeks, according to the classification system of $\mathrm{Pa}$ pile et al. (1978).

\begin{tabular}{ccc}
\hline Grade & N & Frequency \\
\hline Grade I & 23 & $50 \%$ \\
Grade II & 10 & $21.8 \%$ \\
Grade III & 9 & $19.5 \%$ \\
Grade IV & 4 & $8.7 \%$ \\
TOTAL & 46 & $100 \%$ \\
\hline
\end{tabular}


severe. Among all the 46 cases of peri-intraventricular hemorrhage, this condition was diagnosed as bilateral in 42 cases (91.3\%) and unilateral in four cases (8.7\%), among which three were left-side and one was right-side. The time at which peri-intraventricular hemorrhage was diagnosed was before the $4^{\text {th }}$ day of life in 24 cases $(52.3 \%)$, from the $4^{\text {th }}$ to the $10^{\text {th }}$ day of life in 20 cases $(43.4 \%)$ and from the $10^{\text {th }}$ to the $28^{\text {th }}$ day of life in two cases $(4.3 \%)$. In six cases $(13.0 \%)$, there was progression of the peri-intraventricular hemorrhage after the initial diagnosis. Among these six cases, four had an initial diagnosis of peri-intraventricular hemorrhage grade I, of which two evolved to grade II and then one of these evolved to grade III. The other two these six cases initially presented peri-intraventricular hemorrhage grade II and evolved to grade III.

Among all the cases of peri-intraventricular hemorrhage that were studied, four $(8.7 \%)$ evolved with post-hemorrhagic hydrocephaly. Of these, one case required ventriculoperitoneal shunt, while clinical and ultrasonographic follow-up was maintained for the other three cases. Among the four cases with post-hemorrhagic hydrocephaly, three presented peri-intraventricular hemorrhage grade III and one presented peri-intraventricular hemorrhage grade IV.

There were four newborns with presented peri-intraventricular hemorrhage grade IV, and one of them (25\%) developed a porencephalic cyst, while the other three $(75 \%)$ evolved to death (two on the $4^{\text {th }}$ day of life and one on the $10^{\text {th }}$ day of life).

Regarding the severity of peri-intraventricular hemorrhage in relation to gestational age, grade I was most frequently seen in the stratum from 31 weeks to 33 weeks and 6 days $(70.7 \%)$; grade II in the stratum from 25 weeks to 27 weeks and 6 days (35.3\%); grade III in the stratum from 28 weeks to 30 weeks and 6 days (25\%); and grade IV in the stratum from 25 weeks to 27 weeks and 6 days (11.8\%).

Table 2 shows the results relating to the presence of an association between the gestational and perinatal characteristics and the presence or absence of peri-intraventricular hemorrhage. It could be seen that peri-intraventricular hemorrhage became more frequent when the gestational age and birth weight were lower. Among newborns of gestational age $<28$ weeks, the frequency of peri-intraventricular hemorrhage was $37 \%$. Among newborns weighing $<1000 \mathrm{~g}$, the frequency of peri-intraventricular hemorrhage was $43.5 \%$. This condition occurred more frequently among newborns who had undergone reanimation in the delivery room (63\%).

Data on the presence of associations between peri-intraventricular hemorrhage and pathological conditions among the newborns, and between peri-intraventricular hemorrhage and use of certain procedures, are shown in Table 3. It should be noted that all the newborns who evolved with peri-intraventricular hemorrhage had required some type of assisted ventilation before receiving their diagnosis. Peri-intraventricular hemorrhage occurred more frequently in newborns who received exogenous surfactant. However, there was no difference between the cases in which surfactant was applied in the delivery room and 
Table 2. Associations of obstetric, perinatal and neonatal characteristics with the presence or absence of peri-intraventricular hemorrhage among newborns of gestational age less than 34 weeks.

\begin{tabular}{|c|c|c|c|c|c|}
\hline \multirow{2}{*}{ Variable } & \multicolumn{2}{|c|}{ Present $(n=46)$} & \multicolumn{2}{|c|}{ Absent $(n=110)$} & \multirow{2}{*}{ - p-value ${ }^{a}$} \\
\hline & $\mathrm{n}$ & $\%$ & $\mathbf{N}$ & $\%$ & \\
\hline \multicolumn{6}{|l|}{ Chorioamnionitis } \\
\hline Yes & 3 & 6.5 & 8 & 7.3 & 1.000 \\
\hline No & 43 & 93.5 & 102 & 92.7 & \\
\hline \multicolumn{6}{|c|}{ Antenatal corticoids } \\
\hline Yes & 11 & 23.9 & 35 & 31.8 & 0.323 \\
\hline No & 35 & 76.1 & 75 & 68.2 & \\
\hline \multicolumn{6}{|c|}{ Gestational age (weeks and days) } \\
\hline $25 \mathrm{w}$ to $27 \mathrm{w} 6 \mathrm{~d}$ & 17 & 37.0 & 4 & 3.6 & $<0.001$ \\
\hline $28 \mathrm{w}$ to $30 \mathrm{w} 6 \mathrm{~d}$ & 12 & 26.1 & 20 & 18.2 & \\
\hline $31 \mathrm{w}$ to $33 \mathrm{w} 6 \mathrm{~d}$ & 17 & 37.0 & 86 & 78.2 & \\
\hline \multicolumn{6}{|l|}{ Weight (g) } \\
\hline $500-999 \mathrm{~g}$ & 20 & 43.5 & 7 & 6.4 & $<0.001$ \\
\hline $1000-1500 \mathrm{~g}$ & 13 & 28.3 & 48 & 43.6 & \\
\hline$>1500 \mathrm{~g}$ & 13 & 28.3 & 55 & 50.0 & \\
\hline \multicolumn{6}{|c|}{ Apgar score in $1^{\text {st }} \min$} \\
\hline $0-3$ & 11 & 23.9 & 7 & 6.4 & 0.003 \\
\hline $4-6$ & 17 & 37.0 & 32 & 29.1 & \\
\hline $7-10$ & 15 & 32.6 & 65 & 59.1 & \\
\hline No data & 3 & 6.5 & 6 & 5.5 & \\
\hline \multicolumn{6}{|c|}{ Apgar score in $5^{\text {th }} \min$} \\
\hline $0-3$ & 0 & 0 & 0 & 0 & \\
\hline $4-6$ & 13 & 28.3 & 4 & 3.6 & $<0.001$ \\
\hline $7-10$ & 30 & 65.2 & 101 & 91.8 & \\
\hline No data & 3 & 6.5 & 5 & 4.5 & \\
\hline \multicolumn{6}{|c|}{ Reanimation in delivery room } \\
\hline Yes & 29 & 63.0 & 29 & 26.4 & $<0.001$ \\
\hline No & 17 & 37.0 & 81 & 73.6 & \\
\hline \multicolumn{6}{|c|}{ Surfactant in delivery room } \\
\hline Yes & 13 & 28.3 & 17 & 15.5 & 0.064 \\
\hline No & 33 & 71.7 & 93 & 84.5 & \\
\hline \multicolumn{6}{|c|}{ Transferred from another hospital } \\
\hline Sim & 17 & 37.0 & 34 & 30.9 & 0.463 \\
\hline Não & 29 & 63.0 & 76 & 69.1 & \\
\hline
\end{tabular}

${ }^{a}$ Chi-square test. 
Table 3. Associations of neonatal characteristics (pathological conditions, procedures and clinical treatments) with the presence or absence of peri-intraventricular hemorrhage among newborns of gestational age less than 34 weeks.

\begin{tabular}{|c|c|c|c|c|c|}
\hline \multirow{2}{*}{ Variable } & \multicolumn{2}{|c|}{ Present $(n=46)$} & \multicolumn{2}{|c|}{ Absent $(n=110)$} & \multirow{2}{*}{ valor de $\mathrm{p}^{\alpha}$} \\
\hline & $\mathbf{n}$ & $\%$ & $\mathbf{n}$ & $\%$ & \\
\hline \multicolumn{6}{|c|}{ Respiratory distress syndrome } \\
\hline Yes & 41 & 89.1 & 43 & 39.1 & $<0.001$ \\
\hline No & 5 & 10.9 & 67 & 60.9 & \\
\hline \multicolumn{6}{|l|}{ Sepsis } \\
\hline Yes & 42 & 91.3 & 61 & 55.5 & $<0.001$ \\
\hline No & 4 & 8.7 & 49 & 44.5 & \\
\hline \multicolumn{6}{|c|}{ Catheterization of umbilical vein } \\
\hline Yes & 45 & 97.8 & 82 & 74.5 & 0.001 \\
\hline No & 1 & 2.2 & 28 & 25.5 & \\
\hline \multicolumn{6}{|l|}{ Assisted ventilation } \\
\hline Yes & 46 & 100.0 & 100 & 90.9 & --- \\
\hline No & 0 & 0 & 9 & 8.2 & \\
\hline No supplementary $\mathrm{O}_{2}$ & 0 & 0 & 1 & 0.9 & \\
\hline \multicolumn{6}{|l|}{ Exogenous surfactant } \\
\hline Yes & 42 & 91.3 & 50 & 45.5 & $<0.001$ \\
\hline No & 4 & 8.7 & 60 & 54.5 & \\
\hline \multicolumn{6}{|l|}{ Sodium bicarbonate } \\
\hline Yes & 11 & 23.9 & 3 & 2.7 & $<0.001$ \\
\hline No & 35 & 76.1 & 107 & 97.3 & \\
\hline \multicolumn{6}{|l|}{ Inotropes } \\
\hline Yes & 16 & 34.8 & 6 & 5.5 & $<0.001$ \\
\hline No & 30 & 65.2 & 104 & 94.5 & \\
\hline \multicolumn{6}{|l|}{ Adrenalin } \\
\hline Yes & 9 & 19.6 & 1 & 0.9 & $<0.001$ \\
\hline No & 37 & 80.4 & 109 & 99.1 & \\
\hline \multicolumn{6}{|l|}{ Volume expanders } \\
\hline Yes & 19 & 41.3 & 14 & 12.7 & $<0.001$ \\
\hline No & 27 & 58.7 & 96 & 87.3 & \\
\hline \multicolumn{6}{|l|}{ Blood derivatives } \\
\hline Yes & 30 & 65.2 & 21 & 19.1 & $<0.001$ \\
\hline No & 16 & 34.8 & 89 & 80.9 & \\
\hline
\end{tabular}

${ }^{a}$ Chi-square test.

those in which it was applied in the neonatal intensive care unit. It was observed that $97.8 \%$ of newborn submitted to umbilical vein catheterization had peri intraventricular, as well as the high frequency in those who used epinephrine and 
blood products.

The association between intra-hospital outcomes and the presence or absence of peri-intraventricular hemorrhage is described in Table 4. It needs to be highlighted that $37 \%$ of the newborns who presented peri-intraventricular hemorrhage were in hospital for more than 60 days and that $10.9 \%$ of them were also receiving assisted ventilation. Among the newborns who evolved to death, $28.3 \%$ presented peri-intraventricular hemorrhage.

\section{Discussion}

This study demonstrated the prevalence of peri-intraventricular hemorrhage among premature newborns of gestational age less than 34 weeks, the risk factors associated with its development and the relationship with some intra-hospital outcomes (duration of assisted ventilation, length of hospital stay and frequency of occurrence of death), in two neonatal intensive care units in the state of Alagoas.

Over the period analyzed, from May to November 2015, the observed frequency of peri-intraventricular hemorrhage was $29.5 \%$, of which $28.2 \%$ were classified as severe. These frequencies were higher than those of other countries and regions like Japan (10.0\%), Taiwan (14.0\%), Canada (18.0\%) and the United States (19.0\%) [6]. In Brazil, data from 20 university hospitals that were presented in the 2014 annual report of the Brazilian Network for Neonatal Research showed that the incidence of peri-intraventricular hemorrhage among premature

Table 4. Associations of intra-hospital outcomes with the presence or absence of peri-intraventricular hemorrhage among newborns of gestational age less than 34 weeks.

\begin{tabular}{|c|c|c|c|c|c|}
\hline \multirow{2}{*}{ Variable } & \multicolumn{2}{|c|}{ Present $(n=46)$} & \multicolumn{2}{|c|}{ Absent $(n=110)$} & \multirow{2}{*}{$\begin{array}{c}\mathrm{p} \text {-value } \\
\mathrm{p}^{\alpha}\end{array}$} \\
\hline & $\mathbf{n}$ & $\%$ & $\mathbf{n}$ & $\%$ & \\
\hline \multicolumn{6}{|c|}{ Length of hospital stay } \\
\hline 0 to 10 days & 10 & 21.7 & 24 & 21.8 & \multirow{4}{*}{$<0.001$} \\
\hline$>10$ to 28 days & 0 & 0 & 42 & 38.2 & \\
\hline$>28$ to 60 days & 19 & 41.3 & 40 & 36.4 & \\
\hline$>60$ days & 17 & 37.0 & 4 & 3.6 & \\
\hline \multicolumn{6}{|l|}{ Death } \\
\hline Yes & 13 & 28.3 & 16 & 14.5 & \multirow{2}{*}{0.045} \\
\hline No & 33 & 71.7 & 94 & 85.5 & \\
\hline \multicolumn{6}{|c|}{ Duration of assisted ventilation } \\
\hline 0 to 10 days & 15 & 32.6 & 78 & 70.9 & \multirow{4}{*}{$<0.001$} \\
\hline$>10$ to 28 days & 17 & 37.0 & 30 & 27.3 & \\
\hline$>28$ to 60 days & 9 & 19.6 & 2 & 1.8 & \\
\hline$>60$ days & 5 & 10.9 & 0 & 0 & \\
\hline
\end{tabular}

${ }^{a}$ Chi-square test. 
newborns weighing less than $1500 \mathrm{~g}$ was $30 \%$, and that this condition was severe in $9 \%$ of these cases [7].

It is possible that the high prevalence of peri-intraventricular hemorrhage that was observed in the present study, especially among premature newborns of gestational age less than 28 weeks and with birth weight less than $1500 \mathrm{~g}$, may have been influenced by other factors. It needs to be taken into consideration that, over the study period, the bed occupancy rates in the two neonatal intensive care units were high and there were inadequacies regarding the physical facilities, the professional staff per bed ratio and the materials available. In an analysis over a 15-year period conducted in a similar institution in Brazil, it was observed that the peri-intraventricular hemorrhage rate declined from $50.9 \%$ in 2001 to $11.9 \%$ in 2005 , despite an increasing survival rate among extremely premature newborns. In that study, changes to the neonatal intensive care unit that took place during the study period (acquisition of equipment, hiring of professionals and contracting of specialized services) were considered to be important factors in that result [17].

In the present study, no statistically significant associations were found for any of the obstetric or perinatal risk factors, which all presented p-values $>0.05$. However, it had previously been reported that newborns whose mothers had been diagnosed with chorioamnionitis were at significantly higher risk of peri-intraventricular hemorrhage [2] [18]. In the present study, the analysis on this factor was probably impaired by the small number of patients who presented chorioamnionitis or by underreporting, given that the diagnosis was based on a clinical assessment, without any histological analysis.

It is important to note that the frequency of antenatal use of corticoids as a protective factor was low $(29.5 \%)$, in comparison with the frequency presented in the 2014 annual report of the Brazilian Network for Neonatal Research (77.0\%) [7]. This result can possibly be explained by the high number of newborns in the present study who had been transferred from other hospitals (32.7\%). Araujo et al. [19] observed that the rate of corticoid use in the population transferred from elsewhere was $24 \%$, while it was $72.7 \%$ among newborns delivered in the hospital of their study. Moreover, we used data from two or more doses of corticoids, [18] [20] [21] given that some studies have shown that use of only one dose of this medication did not give rise to any significant difference in the incidence of peri-intraventricular hemorrhage [18] [21].

From studying the neonatal risk factors, it could be seen that gestational age less than 28 weeks and birth weight less than or equal to $1500 \mathrm{~g}$ were the dominant factors, thus corroborating the data in the literature [12] [14] [22].

In analyzing the relationship between the Apgar index and peri-intraventricular hemorrhage, it was observed that $46.1 \%$ of the newborns who presented Apgar < 7 in the $5^{\text {th }}$ minute of life also presented the severe form of the disease. This result was concordant with the data in the literature [2] [15] [21].

An association between peri-intraventricular hemorrhage and reanimation in 
the delivery room has been described in the literature. This was due to changes to the cerebra blood flow: initially through the presence of hypoxia and subsequently through reperfusion after cardiopulmonary reanimation [5] [14]. In the present study, higher frequency of peri-intraventricular hemorrhage was observed among the newborns who underwent reanimation in the delivery room than was reported by other authors [2] [21]. This difference may have been related to the lack of adequate support for reanimation in the delivery room that the institutions of the present study were experiencing at the time of this study.

In the present study, no significant differences relating to peri-intraventricular hemorrhage and transportation between hospitals were seen. Longhini et al. [23] conducted a case-control study to evaluate neonatal morbidities in relation to transfers and did not observe any impact of the frequency of peri-intraventricular hemorrhage. However, in a case-control study conducted in China, in which gestational ages and birth weights of premature newborns were paired, a statistically significant relationship between transportation of newborns between hospitals and occurrences of peri-intraventricular hemorrhage was observed [15]. Therefore, it has been suggested that deliveries of premature newborns should be done at tertiary-level centers, so as to avoid transportation between hospitals [15] [19] [23].

Regarding morbidities and treatments among the newborns of the present study, the high frequencies of peri-intraventricular hemorrhage among the newborns with the following conditions can be highlighted: respiratory distress syndrome, sepsis, use of exogenous surfactants (albeit without any difference between doing this in the delivery room and doing it in the neonatal intensive care unit), catheterization of the umbilical vein, mechanical ventilation and blood transfusion. These morbidities and treatments increase the velocity of cerebral blood flow and lead to greater risk of bleeding [5], and this has also been observed by other authors [1] [14] [20] [21] [22] [23] [24].

The frequency of neonatal sepsis was high in the population of the present study, compared with what had previously been seen in other studies [2] [14] [21]. This difference may have been related to how sepsis was classified, considering that in the present study, it was classified clinically. It is possible that in reality the estimates should be higher, beyond what was seen in each neonatal intensive care unit, given that some of these units, like those of the present study, maintain occupation levels much above their capacity, because of a shortage of beds in the state of Alagoas. This would thus increase the possibility of complications among the newborns.

In assessing intra-hospital outcomes, it was seen that the newborns with peri-intraventricular hemorrhage had longer duration of assisted ventilation and longer hospital stay. Presence of greater severity of the disease was associated with higher frequency of death, and this finding was consonant with the data in the literature [12] [14] [18] [20] [25] [26] [27].

Among the limitations of the present study, the time at which the first ultra- 
sound examination was performed should be highlighted. This is important in evaluating the obstetric and perinatal risk factors within the first hours of life. In the present study, this examination was done no later than the fourth day of life.

This study was the first of its kind in the State of Alagoas, Brazil. Although the present data do not show new discoveries, the knowledge of the profile of preterm newborns with peri-intraventricular is important for its control, since advances in perinatal and neonatal medicine provide the possibility of greater viability for extreme preterm infants. Future studies could be directed towards neurological evaluations on these newborns.

\section{Conclusion}

In conclusion, the present study showed that there was high prevalence of peri-intraventricular hemorrhage, and especially of severe forms of this condition. Perinatal and neonatal factors were associated with greater risk of developing peri-intraventricular hemorrhage, and the intra-hospital outcomes studied were more frequent among the newborns with this disease.

\section{Conflicts of Interest}

The authors declare no conflicts of interest regarding the publication of this paper.

\section{References}

[1] Lee, J.Y., Kim, H.S., Jung, E., Kim, E.S., Shim, G.H., Lee, H.J., et al. (2010) Risk Factors for Periventricular-Intraventricular Hemorrhage in Premature Infants. Journal of Korean Medical Science, 25, 418-424.

[2] Payne, A.H., Hintz, S.R., Hibbs, A.M., Walsh, M.C., Vohr, B.R., Bann, C.M., et al. (2013) Neurodevelopmental Outcomes of Extremely Low-Gestational-Age Neonates with Low-Grade Periventricular-Intraventricular Hemorrhage. JAMA Pediatrics, 167, 451-459. https://doi.org/10.1001/jamapediatrics.2013.866

[3] Tsai, A.J., Lasky, R.E., John, S.D., Evans, P.W. and Kennedy, K.A. (2014) Predictors of Neurodevelopmental Outcomes in Preterm Infants with Intraparenchymal Hemorrhage. Journal of Perinatology, 34, 399-404. https://doi.org/10.1038/jp.2014.21

[4] Bolisetty, S., Dhawan, A., Abdel-Latif, M., Bajuk, B., Stack, J. and Lui, K. (2014) Intraventricular Hemorrhage and Neurodevelopmental Outcomes in Extreme Preterm Infants. Pediatrics, 133, 55-62. https://doi.org/10.1542/peds.2013-0372

[5] Whitelaw, A. (2011) Core Concepts: Intraventricular Hemorrhage. NeoReviews, 12, e94-e101. https://doi.org/10.1542/neo.12-2-e94

[6] Su, B.H., Hsieh, W.S., Hsu, C.H., Chang, J.H., Lie, R. and Lin, C.H. (2015) Neonatal Outcomes of Extremely Preterm Infants from Taiwan: Comparison with Canada, Japan, and the USA. Pediatrics \& Neonatology, 56, 46-52. https://doi.org/10.1016/j.pedneo.2014.05.002

[7] Rede Brasileira de Pesquisas Neonatais (2014) Relatório anual 2014. http://www.redeneonatal.fiocruz.br

[8] Papile, L.A., Burstein, J., Burstein, R. and Koffler, H. (1978) Incidence and Evolution of Subependymal and Intraventricular Hemorrhage: A Study of Infants with 
Birth Weights Less than 1,500gm. The Journal of Pediatrics, 92, 529-534. https://doi.org/10.1016/S0022-3476(78)80282-0

[9] Brezan, F., Ritivoiu, M., Dragan, A., Codreanu, I., Raducanu, D., Feier, D., et al. (2012) Preterm Screening by Transfontanelar Ultrasound-Result of a 5 Years Cohort Study. Medical Ultrasonography, 14, 204-210.

[10] Brouwer, A.J., Groenendaal, F., Benders, M.J. and De Vries, L.S. (2014) Early and Late Complications of Germinal Matrix-Intraventricular Haemorrhage in the Preterm Infant: What Is New? Neonatology, 106, 296-303. https://doi.org/10.1159/000365127

[11] Klebermass-Schrehof, K., Czaba, C., Olischar, M., Fuiko, R., Waldhoer, T., Rona, Z., et al. (2012) Impact of Low-Grade Intraventricular Hemorrhage on Long-Term Neurodevelopmental Outcome in Preterm Infants. Child's Nervous System, 28, 2085-2092. https://doi.org/10.1007/s00381-012-1897-3

[12] Goldstein, RF., Cotton, C.M., Shankaran, S., Gantz, M.G. and Poole, W.K. (2013) Influence of Gestational Age on Death and Neurodevelopmental Outcome in Premature Infants with Severe Intracranial Hemorrhage. Journal of Perinatology, 33, 25-32. https://doi.org/10.1038/jp.2012.91

[13] Kim, K.R., Jung, S.W. and Kim, D.W. (2014) Risk Factors Associated with Germinal Matrix-Intraventricular Hemorrhage in Preterm Neonates. Journal of Korean Neurosurgical Society, 56, 334-337. https://doi.org/10.3340/jkns.2014.56.4.334

[14] Caro-López, A.M., Barrera-de-León, J.C., Dominguez-Sánchez, H., Alejandrina Castillo, S.R. and Higareda-Almaraz, M.A. (2010) Evaluación de factores prenatales, perinatales Para hemorragia Intraventricular en prematuros menores de 33 semanas de edad gestacional. Gaceta medica de Mexico, 146, 376-382.

[15] Rong, Z., Liu, H., Xia, S. and Chang, L. (2012) Risk and Protective Factors of Intraventricular Hemorrhage in Preterm Babies in Wuhan, China. Childs Nervous System, 28, 2077-2084. https://doi.org/10.1007/s00381-012-1875-9

[16] Castro, M.P., Rugolo, L.M.S.S. and Margotto, P.R. (2012) Sobrevida e morbidade em prematuros com menos de 32 semanas de gestação na região central do Brasil. Revista Brasileira de Ginecologia e Obstetrícia, 34, 235-242. https://doi.org/10.1590/S0100-72032012000500008

[17] Marba, S.T.M., Caldas, J.P.S., Vinagre, L.E.F. and Pessoto, M.A. (2011) Incidência de hemorragia Peri-intraventricular em recém-nascidos de muito baixo peso: análise de 15 anos. Jornal de Pediatria, 87, 505-511.

[18] Caldas, J.P., Braghini, C.A., Mazzola, T.N., Vilela, M.M. and Marba, S.T. (2015) Peri-Intraventricular Hemorrhage and Oxidative and Inflammatory Stress Markers in Very-Low Birth Weight Newborns. Jornal de Pediatria, 91, 373-379. https://doi.org/10.1016/j.jped.2014.09.008

[19] Araújo, B.F., Zatti, H., Oliveira Filho, P.F., Coelho, M.B., Olmi, F.B., Guaresi, T.B., et al. (2011) Effect of place of birth and transport on morbidity and mortality of preterm newborns. Jornal de Pediatria, 87, 257-262.

[20] Agarwal, P., Sriram, B. and Rajadurai, V.S. (2015) Neonatal Outcome of Extremely Preterm Asian Infants $\leq 28$ Weeks over a Decade in the New Millennium. Journal of Perinatology, 35, 297-303. https://doi.org/10.1038/jp.2014.205

[21] Pekcevik, Y., Pasinli, A., Ozer, E.A. and Erdogan, N. (2014) Risk factors of Germinal Matrix Intraventricualr Hemorrhage in Premature Infants. Iranian Journal of Pediatrics, 24, 191-197.

[22] Lizama, O., Hernández, H., Rivera, F. and Tori, A. (2014) Incidência de la hemorragia intraventricular en prematuros de muy bajo peso y sus factores asociados en un hospital 
nacional de Lima. Revista Medica Herediana, 25, 60-67.

https://doi.org/10.20453/rmh.v25i2.246

[23] Longhini, F., Jourdain, G., Ammar, F., Mokthari, M., Boithias, C., Romain, O., et al. (2015) Outcomes of Preterm Neonates Transferred between Tertiary Perinatal Centers. Pediatric Critical Care Medicine, 16, 733-738.

https://doi.org/10.1097/PCC.0000000000000482

[24] Nayeril, F., Dalili, H., Nili, F., Amini, E., Ardehali, A., Mansoori, B.K., et al. (2013) Risk Factors for Neonatal Mortality among Very Low Birth Weight Neonates. Acta Medica Iranica, 51, 297-302.

[25] Ogata, J.F.M., Machado Fonseca, M.C.M., Miyoshi, M.H., Almeida, M.F.B. and Guinsburg, R. (2016) Custos da hospitalização de recém-nascidos pré-termo: impacto da corticoterapia antenatal. Jornal de Pediatria, 92, 24-31.

https://doi.org/10.1016/j.jped.2015.03.004

[26] Sousa, D.S., Sousa Júnior, A.S., Santos, A.D., Melo, E.V., Lima, S.O., Almeida Santos, M.A., et al. (2017) Morbidade em recém-nascidos prematuros de extremo baixo peso em unidade de terapia intensiva neonatal. Revista Brasileira de Saúde Materno Infantil, 17, 139-147. https://doi.org/10.1590/1806-93042017000100008

[27] Silva, L.R., Iser, B.P., Tartare, B. and Bonett, H.S. (2015) Aspectos perinatais relacionados à hemorragia intracraniana em recém-nascidos de muito baixo peso no Sul do Brasil. Revista Brasileira de Ginecologia e Obstetrícia, 37, 159-163. https://doi.org/10.1590/SO100-720320150004973 